\title{
DIGITAL INVASIONS: FROM POINT CLOUDS TO HISTORICAL BUILDING OBJECT MODELING (H-BOM) OF A UNESCO WHL SITE
}

\author{
F. Chiabrando ${ }^{\text {a }}$, M. Lo Turco ${ }^{a}$, C. Santagati ${ }^{\text {b* }}$ \\ ${ }^{a}$ Dept of Architecture and Design, Politecnico di Torino, viale Mattioli n.39 10125, Torino, Italy - (filiberto.chiabrando, \\ massimiliano.loturco)@polito.it \\ ${ }^{\mathrm{b}}$ Dept. of Civil Engineering and Architecture, Università di Catania, Via Santa Sofia n. 64 95123, Catania, Italy- \\ csanta@dau.unict.it
}

Commission II

KEY WORDS: Laser scanning, H-BIM, digital cultural heritage, SfM, Level of Accuracy

\begin{abstract}
:
The paper here presented shows the outcomes of a research/didactic activity carried out within a workshop titled "Digital Invasions. From point cloud to Heritage Building Information Modeling" held at Politecnico di Torino ( $29^{\text {th }}$ September $-5^{\text {th }}$ October 2016). The term digital invasions refers to an Italian bottom up project born in the 2013 with the aim of promoting innovative digital ways for the enhancement of Cultural Heritage by the co-creation of cultural contents and its sharing through social media platforms. At this regard, we have worked with students of Architectural Master of Science degree, training them with a multidisciplinary teaching team (Architectural Representation, History of Architecture, Restoration, Digital Communication and Geomatics). The aim was also to test if our students could be involved in a sort of niche crowdsourcing for the creation of a library of H-BOMS (HistoricalBuilding Object Modeling) of architectural elements.
\end{abstract}

\section{INTRODUCTION}

In the last years we have lived one of the most significant technological innovation in the field of Architecture / Construction / Engineering and Facility Management (AEC/FM) community, with the introduction of semantically rich digital facility models, known as Building Information Modeling (BIM), specially for new building construction.

If in this domain the road seems already drawn, in the field of Cultural Heritage this topic has not have been fully explored, in spite of all the advantages that the adoption of this methodology could bring in the field of Cultural Heritage conservation and management. There is still a lack of standards in terms of accuracy, precision, quality and infographic representation and data enrichment compliant with the acquired data.

Furthermore, Cultural Heritage sites and our valuable historical architectural heritage across Europe require high-resolution 3D models in order to achieve a significant added value from their digitalization. Moreover, the passage from the point cloud to the BIM is not so foregone. Several issues have to be taken into account also because available commercial platforms do not include libraries of historical elements.

The paper here presented shows the outcomes of a research/didactic activity carried out within a workshop titled "Digital Invasions. From point cloud to Heritage Building Information Modeling" held at Politecnico di Torino (29 September $-5^{\text {th }}$ October 2016). The term digital invasions refers to an Italian bottom up project born in the 2013 with the aim of promoting innovative digital ways for the enhancement of Cultural Heritage by the co-creation of cultural contents and its sharing through social media platforms (Bonacini et al.,2014).

We have worked with students of Architectural Master of Science degree, training them with a multidisciplinary teaching team (Architectural Representation, History of Architecture, Restoration, Digital Communication and Geomatics). The aim was double: giving the proper critical insights to handle this complex topic to future professionals and testing if students after this training could be involved in a sort of niche crowdsourcing for the creation of a library of H-BOMS of architectural elements.

During the workshop a complete workflow to obtain H-BOMs (Historical Building Object Modeling) by using commercial BIM platforms (Revit @ Autodesk and Pointsense plugin) up to the sharing on the web was tested on architectural elements such as windows and doors of Valentino Castle, which is mentioned in UNESCO WHL (World Heritage List) as part of the "Savoy residences".

\section{RELATED WORKS}

The digital recording of cultural heritage sites using laser scanning and photogrammetry has become a topic of great interest in the field of conservation and cultural heritage.

The spread of Image-based 3D modeling techniques, through digital photogrammetry free, low cost and open source packages, have drastically increased in the past few years, especially in the field of Cultural Heritage. Many researchers have carried out several tests that have demonstrated the metric reliability of Structure from Motion (SfM) techniques for architectural elements where other techniques (such as Terrestrial Laser Scanning- TLS) are costly, not sufficiently dense or not easy to access (Chiabrando et al., 2013; Grussenmeyer et al., 2008; Kadobayansky et al., 2004; Inzerillo et al., 2013; Lichti et al., 2002; Manferdini et al., 2013; Remondino et al., 2014; Roncella, 2011). Moreover, tests performed by several research teams (Gaiani et al., 2016) have demonstrated that these techniques are strictly dependent on the quality of the dataset (network, image

\footnotetext{
* Corresponding author
} 
resolution, radiometric quality) and are suitable for medium size objects, such as architectural elements and details.

Although data collection technologies are now very efficient and automated, the processing of this data is still time consuming

Regarding to H-BIM methodology, very little research has been undertaken to understand the potential of BIM for heritage buildings (Del Giudice et al., 2013; Fai et al., 2011; Hichri et al., 2013; Volk et al., 2014). The need to define a BIM based approach deals with the lack of specific components/tools for historical architecture available for commercial BIM platforms (Tang et al., 2010; Thomson et al., 2015; Chiabrando et al., 2016). The reconstruction of complex shapes seems to be a challenging task.

In literature, some works show several steps in 3D HBIM modeling (Murphy et al., 2013); these workflows use different software with the necessary format conversion and we mainly observe a 2D simplification with slices of point clouds to build up the 3D model.

In some work related to H-BIM, some samples of reconstruction of the existing condition have been described, often suggesting the generation of a semantic model based on a constant comparison between the information included in the historical treatises and the profiles achievable from a point cloud (Apollonio et al., 2013; De Luca et al., 2005; Fai et al., 2014). Others, instead, suggest the setting up of a library of historical building object models $(\mathrm{H}-\mathrm{BOM})$ that currently does not exist starting from the digital survey of an artifact (Quattrini et al., 2015) considering also the possibility to reuse the component (Oreni et al., 2013; Biagini et al., 2014; Santagati et al., 2016).

The aim to get a "rigorous BIM" (Biagini et al. 2016; Brumana et al., 2013) is related to the crucial transition from the point cloud to the intelligent parametric object, introducing the concept of level of accuracy. In other words, the point cloud can be considered a digital copy of the object that preserves its geometric features (irregularities, deformations, etc.): some authors carry out a comparison - point cloud to model - to evaluate if the deviation is in keeping with the scope of the $\mathrm{H}$ BIM (Quattrini et al., 2016). Others prefer to perform the 3D modeling in other platforms able to create and manage NURBS surfaces: they use proper protocols to convert NURBS into parametric surfaces then uploaded in BIM platforms.

Other studies refer to the definition of a "rigorous BIM", meaning as the complete exploitation of BIM approaches for Cultural Heritage buildings, not only in terms of geometric accuracy, but also considering other features (parametric objects, relations, attributes, correct setting of Grade and LoD specification, as later explained in detail).

\section{VALENTINO CASTLE WHL SITE}

The Valentino Castle (Castello del Valentino) is a historic building in the north-west Italian city of Turin. It is located in Parco del Valentino on the banks of Po river, and is the seat of the Architecture Faculty of the Politecnico di Torino. It is one of the Residences of the Royal House of Savoy included in the list of UNESCO World Heritage Sites in 1997. Even if the castle is considered by many as the perfect expression of Piemontese baroque, however, it is characterized by many modification that have to be taken into account for a proper study. The building dates back to the Sixteenth century, when it was built a riverside shooting lodge made by a simple wing and a watchtower, the traces of this last one are visible at the base of the south tower.

In the first half of the Seventeenth century, the building was transformed into a castle according to the will of Queen
Christina of France. The French traits are well recognizable in the roofing, extraneous to the Turin context and made by Savoyard wooden master craftsman.

Amedeo and Carlo di Castellamonte built a monumental body parallel to the river, redoubled the towers, and added two pavilions opposite the river, which were connected to the main building by two wings of terraced porches. The castle was not designed as a residence but rather with representation /entertainment scope and mainly for a summer use.

On the death of Queen Christina in 1661, the castle was abandoned. During the Eighteenth Century the court was used as the starting point for hunting expeditions, under Napoleon it became the first school of Veterinary and then firehouse.

In 1858, on the occasion of the National Exhibition, there were realized new spaces to host the event at the behest of Count Cavour: Domenico Ferri and Luigi Tonta designed galleries on two levels, large as the towers. This enlargement was made in a historicist language with the intention of creating an architectural mimesis, however, the nineteenth-century technology made it possible to realize windows of greater amplitude and more detailed decorations, which today allow distinguishing the works dating to different times. At the same time they were also undertaken the restoration and renovation of the Seventeenth-Century decorations.

Afterwards the building (Figure 1) was designated as the seat of the Royal Application School for Engineers and since 1906 became the seat of the Politecnico di Torino.

This latest function brought the need to make the building more accessible from the city: the exedra of the court was destroyed, so that the main front became the one overlooking Corso Marconi, furthermore to meet the needs of new spaces it was created a new wing parallel to the river.

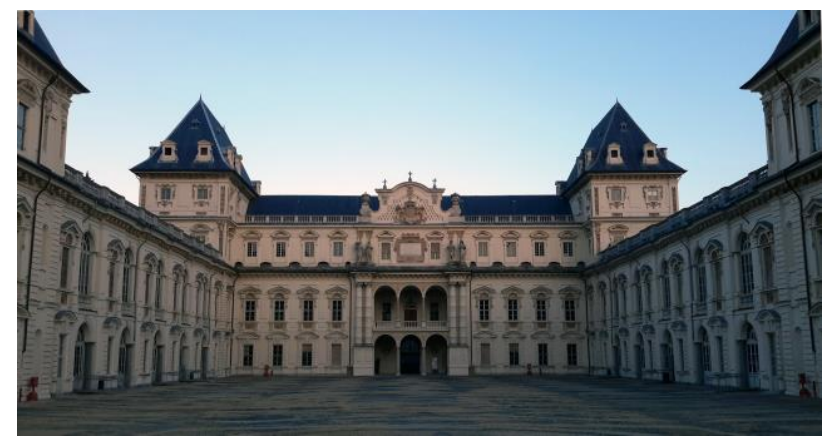

Figure 1. View of the Valentino Castle courtyard

During the Second World War the central loggia underwent some extensive damage caused by the bombing, restoration works began between 1947 and 1948.

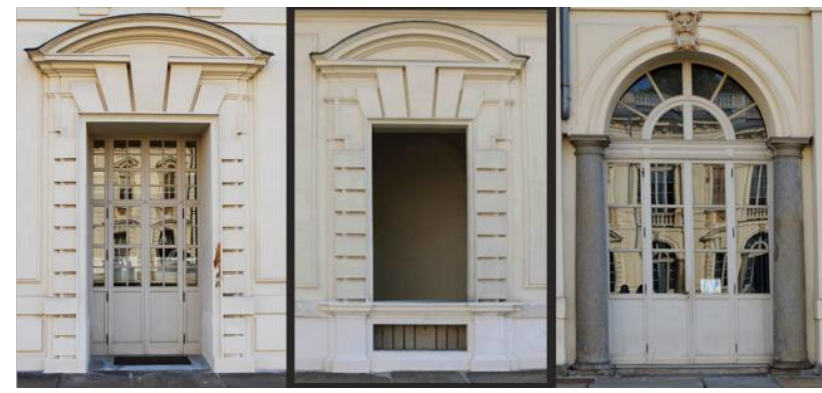

Figure 2. View of some of the analyzed architectural elements

Within this research we take into consideration windows and doors facing the court (Figure 2), these are architectural elements dating back to Seventeenth Century. 
Other restoration works were made on the occasion of the centenary of the unification of Italy and then in the '70s when an invasive intervention compromised the building's color facades. The last restoration was completed at the beginning of the 2000s thanks to the Olympic funding.

\section{METHODOLOGY}

The applied methodology covers a full digital workflow to obtain H-BOMs (Historical Building Object Modeling) of the identified architectural elements of the castle courtyard.

For 3D data acquisition, we used both TLS (Terrestrial Laser Scanner) surveying and photogrammetric SfM (Structure from Motion) based techniques in order to carry out a comparison, both in terms of accuracy, density and file size.

After the acquisition and the first processing steps the obtained point clouds have been imported into BIM platform in order to achieve a semantic aware 3D object. In the employed platforms both the Level of Accuracy (referred to the specific geometrical features) and the Level of Development (intended as the rational collection of several information useful to describe not geometrical features) were measured.

In other words, the final aim of the described activity was to reason both on LoD and on the contents related to Graphic Detail (GraDe), closely consistent to the metric accuracy gained by the metric acquisition.

Doing that, the database linked to the BIM model can be populated by many other information such as the collection of original drawings available in specific historical paper archives, the finding of old and more recent pictures, data related to the decays including observations, material description and technicalities useful to figure out future intervention, only to name a few.

Thus, the applied methodology can be summarized as follows:

1. GCPs and CPs (Ground Control Points and Check Points survey) using traditional topographic approach;

2. Photogrammetric data acquisition and processing by using both desktop and web based packages based on SFM algorithms;

3. Terrestrial Laser Scanner data acquisition;

4. Comparison between TLS and SfM point clouds;

5. 3D modeling in BIM environment;

6. Definition of Graphic Detail according to the Level of Accuracy related to the metric survey;

7. Data enrichment related to the definition of new infographic parameters useful to define multiple Level of Development, according to several data collected during the integrated survey;

8. Sharing of the obtained virtual models on the web.

\subsection{D data acquisition and processing}

Nowadays it is very easy, also for a not photogrammetric expert achieve a 3D model (point cloud or textured mesh) starting from a dataset of $2 \mathrm{D}$ images. Often, however, the user is unaware of the procedures and algorithms, and is incapable to understand if the achieved 3D model fits with the scope of his work.

The aim of this step was to give our students the fundamental skills and awareness on the use of SfM techniques (both web and desktop packages) critically comparing them with TLS ones, reasoning on quality of the dataset (in terms of network, image resolution, radiometric quality) that can be considered suitable for medium/large size objects, such as architectural elements and details.

\subsubsection{Topographic survey}

According to the typical approach for the realization of a $3 \mathrm{D}$ metric survey in the acquired area, several Ground Control Points (GCPs) and Check Points (CPs) were acquired. For the measurements operation a traditional no-prism Total Station was employed. The reference system was set-up according to the GNSS network of the Valentino Castle realized in 2012 (Guardini \& Spanò 2012). Since the area of interest was recently restored actually is forbidden to positioning markers (with glue, tape or other systems) on the plaster surface, as a consequence only natural points were surveyed for the GCPs and CPs collection.

\subsubsection{Photogrammetric acquisition and processing}

The photogrammetric data acquisition was performed in order to realize a point cloud suitable for the realization of a 3D BIM based model with an accuracy that follow the characteristic of a $1: 50$ representation $( \pm 1 \mathrm{~cm})$.

According to the general rules for the realization of a correct SfM based photogrammetric survey (Remondino 2011, Remondino et al., 2014, Samaan et al., 2013) the following parameters were used:

\section{Acquisition of normal and convergent images Overlapping $\geq 80 \%$}

During the acquisition process in order to evaluate the final models different cameras were employed (reflex, bridge, mirror less and compact). First of all in order to evaluate the shooting distance the empirical photogrammetric "rule" that specify that the image scale need to be 5-6 time larger than the survey scale was used. Furthermore, according to the characteristics of the employed camera the ground sample distance GSD was calculated as well. In the next Figure 3 a part of the dataset employed for one of the surveyed windows of the Castle.

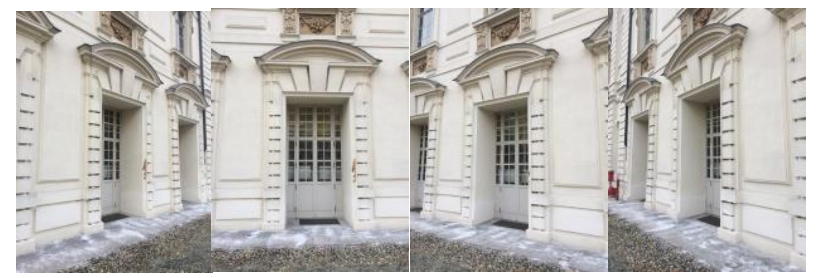

Figure 3. Part of a dataset acquired by a Canon 600D with a 18 $\mathrm{mm}$ (shooting distance $=3 \mathrm{~m} ; \mathrm{GSD}=0.7 \mathrm{~cm}$ )

All the acquired images were processed in two well-known commercial software: Agisoft Photoscan and Autodesk Recap.

As is mentioned before the main object were the realization of a complete point cloud for the next 3D modeling phase that was realized using Autodesk Revit software.

Using both the software the typical workflow was followed (To et al., 2015), image alignment, geo-referentation (Figure 4), bundle block adjustment and dense cloud extraction.

As result two point clouds were achieved with respectively about 1.500.000 points (high setting for the point cloud generation) and 800.000 points using Recap.

In the following Figure 5 the screen shot of the achieved point clouds are reported 

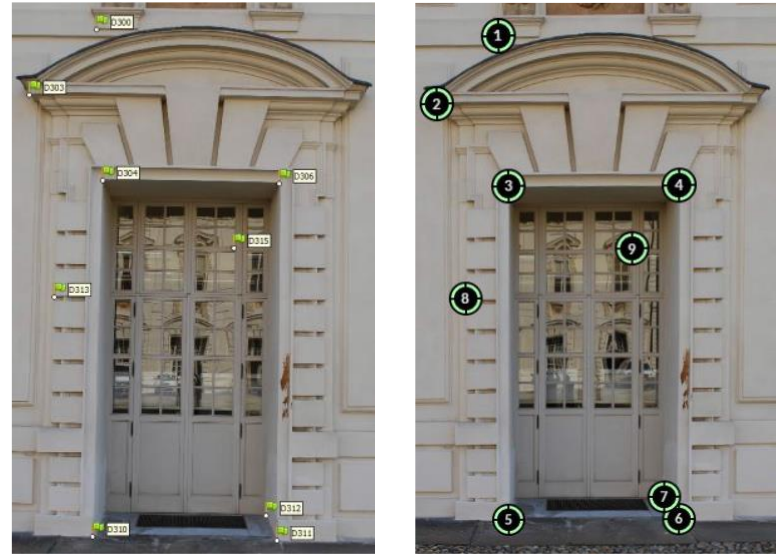

Figure 4 The employed GCPs in Photscan (left) and ReCap (right)
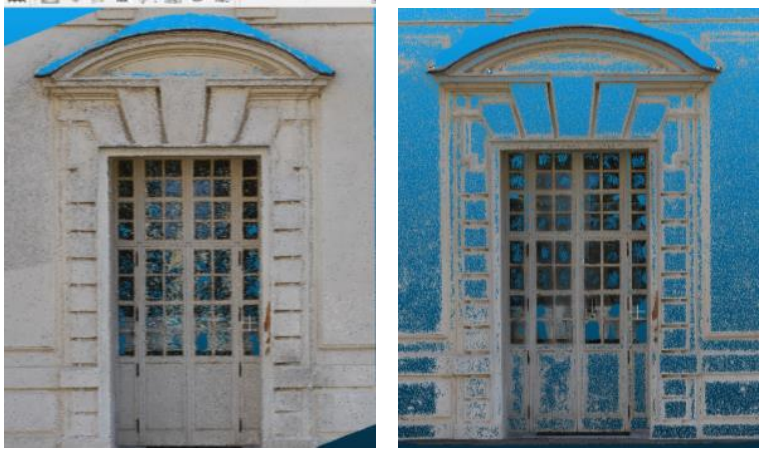

Figure 5. Point cloud generated using Photoscan (left) and Recap (right)

As is possible to notice from Figure 5 in the upper part of the window no data are available since only terrestrial images without any elevation device were acquired. This lack of information has been bypassed using a reconstruction based on the well known geometry of the analyzed part.

After the point clouds generation, the next step was the upload of the point cloud in Revit using the plug-in Point Sense from Faro for the generation of the 3D model in BIM environment. This part is described in the next section 4.3.

\subsubsection{TLS acquisition and processing}

In order to evaluate the possible differences in the generation of the final 3D BIM model a complete TLS survey of the same object was performed as well. In the analyzed area, the Faro Focus ${ }^{3 \mathrm{~d}}$ laser was employed. The acquisition settings were setup at a resolution of $1 / 4$ (Pt. distance $6.1 \mathrm{~mm}$ ) and quality of $4 \mathrm{x}$ (each point will be measured $4^{\text {th }}$ time). The acquisition process has been realized with large overlapping between adjacent scans (more than $60 \%$ ) in order to obtain a very dense final point cloud able to accurately document the acquired areas.

After the data acquisition, the obtained scans were processed using Scene (Faro software) following the next step:

- $\quad$ Point cloud coloring (using the images acquired by the scan)

Registration and geo-referencing (using the measured GCPs)

Cleaning (all the part not connected to object were deleted)
Data exporting (the final point cloud was exported in an interoperable format).

In Figure 6 the complete achieved point cloud is reported.
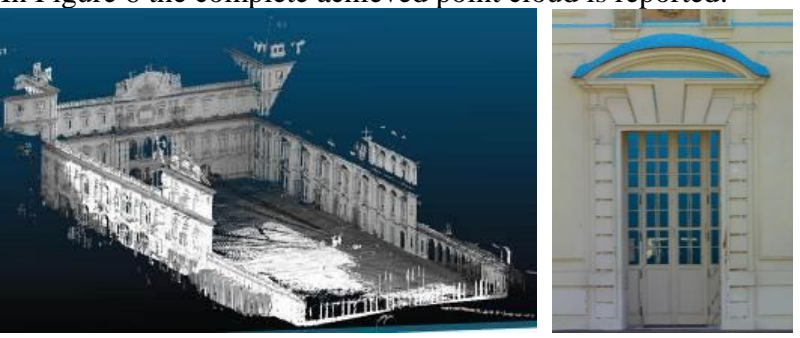

Figure 6 General view of the realized TLS survey (left), zoom on the acquired windows (right).

\subsection{Comparison between TLS and SfM techniques}

After the acquisition and processing a comparison on the achieved results has been performed. The analysis where carried out using Cloud compare Software in order to evaluate first of all the mean density of the clouds, moreover the discrepancy evaluation of the achieved clouds has been performed using as ground truth the TLS point cloud.

In the next Figure 7 the density on an analyzed window is reported.

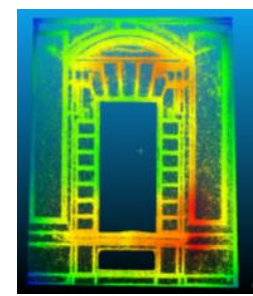

A

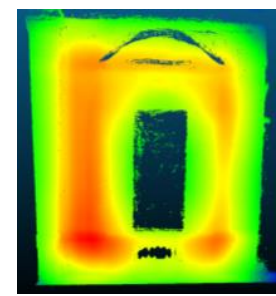

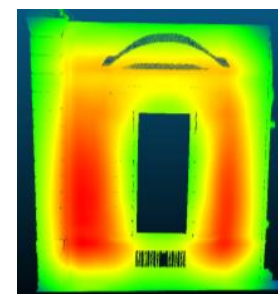

Figure 7. Point cloud density visualization (in red are reported the areas with an higher density) a: ReCap cloud (mean density 19.000 pt sq.m), b:Photoscan cloud (mean density 67.000 pt sq

$\mathrm{m})$, c: TLS point cloud (mean density $110.000 \mathrm{pt}$ sqm).

Finally according to the followed methodology in order to summarize some pro and cons the next table has been realized.

\begin{tabular}{|l|c|c|c|}
\hline & TLS & $\begin{array}{c}\text { SfM } \\
\text { (Photoscan) }\end{array}$ & SfM (ReCap) \\
\hline Cost (instrument) & --- & $\begin{array}{c}- \text { (Reflex } \\
\text { camera) } \\
\text { (mirror less } \\
\text { camera) }\end{array}$ & $\begin{array}{c}\text { (Reflex camera) } \\
+ \text { (mirror less } \\
\text { camera) }\end{array}$ \\
\hline Cost (software) & + & ++ & +++ \\
\hline $\begin{array}{l}\text { Time for data } \\
\text { acquisition }\end{array}$ & +++ & + & + \\
\hline $\begin{array}{l}\text { Time for data } \\
\text { processing }\end{array}$ & ++ & - & ++ \\
\hline Easy to use & +++ & + & ++ \\
\hline Density & +++ & ++ & + \\
\hline Accuracy & +++ & ++ & ++ \\
\hline
\end{tabular}

Table 1. Comparison of the used methods and instruments 
The table report a very simple evaluation of the used approach according to some important parameters: cost of the employed instrument, cost of the software, processing time, accuracy and the density of the final point cloud.

\subsubsection{TLS vs Photoscan:}

Regarding the discrepancy connected to the TLS data of the achieved point cloud using Phototoscan in the next figures are reported the results.

As is possible to notice from Figure 8 the point cloud achieved by the SfM process regarding the first window is comparable with the TLS one since the discrepancy of more than the $80 \%$ of points is under $2 \mathrm{~cm}$ and could be considered in the tolerance of the methods. On the other hand the discrepancy between the point clouds achieved for the second windows are larger, only the $30 \%$ of points are under $2 \mathrm{~cm}$.

In this case the problem is connected to the employed camera (compact) that in Photoscan delivery a very noisy point cloud not suitable for an accurate 3D modeling phase.
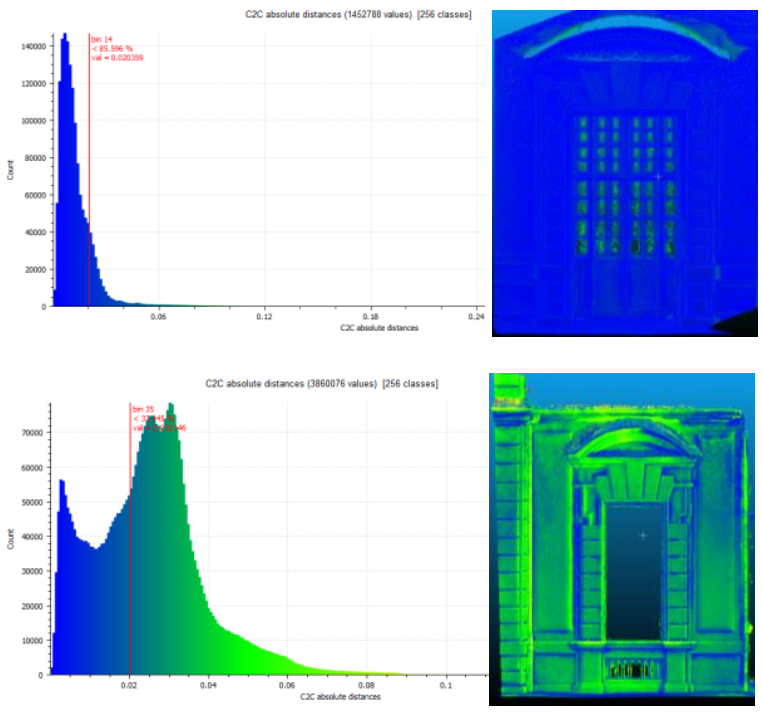

Figure 8. Comparison between TLS point cloud and Photoscan point cloud on two windows of the castle

\subsubsection{TLS vs Recap:}

The discrepancy were evaluated as well with the point clouds obtained by ReCap and in the following Figure 9 are reported the results.

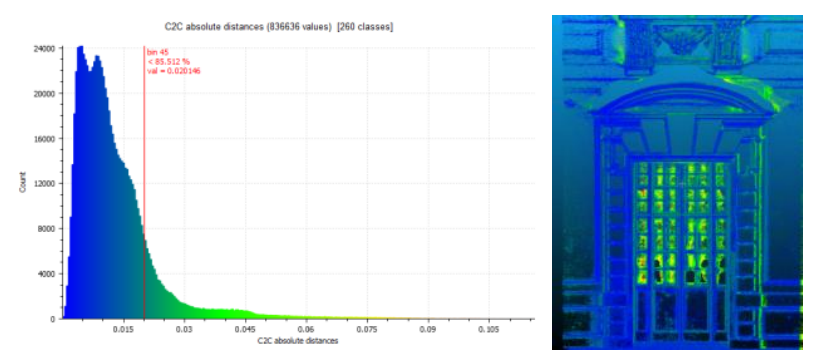

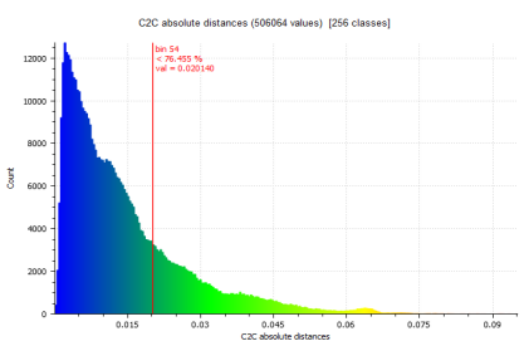

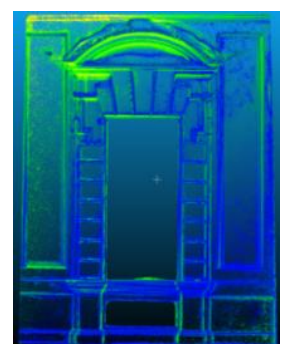

Figure 9. Comparison between TLS point cloud and ReCap point cloud on two windows of the castle

Using ReCap both the achieved point clouds were obtained with a good accuracy compared with the TLS data since more than $85 \%$ for the first windows and more than $75 \%$ for the second of the points have a discrepancy that is under $2 \mathrm{~cm}$.

As was stated above the achieved point clouds were used in the BIM software in order to generate the final 3D models.

\subsection{D modeling in BIM environment}

The following step of the work involved the students in the passage from the discrete model (point cloud) to a semanticaware H-BOM. Students had to study the geometric features of the objects to be modelled, trying to formalize the semantic structure that defines the hierarchies between the whole and its parts, the shapes and the compositional rules in order to find the proper reference planes, rules and constrains to assign in the BIM environment. In this case, historical architecture knowledge-based approach is fundamental for single architectural components recognition, and the understanding of their links and relationships with the whole architectural building is crucial to achieve a proper classification and semantic decomposition of the architectural elements and the different details that form them (De Luca, 2006). Furthermore, after identifying the elements, it is mandatory to understand the geometrical rules (extrusion, revolution) that generate the several surfaces and a set of $2 \mathrm{D}$ profiles that describe it (Figure $10)$.

The best way to obtain a BOM object using BIM platform is to use family/library editors which usually do not allow to import directly point clouds. In this workshop we tested the use of PointSense for Revit, a Kubit plugin resell by Faro that allows the user to import the whole point cloud or a part of it directly into Revit family editor. Pointsense allows you to easily extract x-ray ortho-view from the point-cloud which are georeferenced in the same reference system.

So, ortho-images and segmented/cropped point cloud are the basic data imported for further processing within the family editor. Doing that, critic interpretation of data is favoured because point data redundancy is abstracted to the essential object skeleton lines.

This approach is similar to the use of in situ dimensioned sketches as trace, with the advantage to have a point cloud as reference that could be visualized, cropped and analysed in realtime.

This brings to a proper data interpretation and discretization: through the use of reference planes and reference lines the skeleton of the new parametric component can be outlined; the following dimension and conversion into parametric variables will guarantee the geometric flexibility of BIM components. 


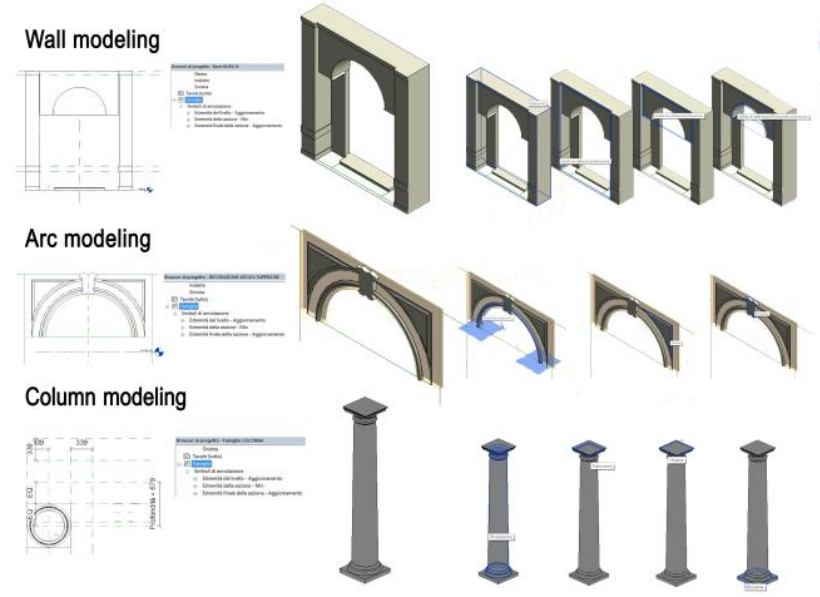

Figure 10.3D semantic modeling of architectural subcomponents

Another relevant issue is to define, before starting the $3 \mathrm{~d}$ modeling, the level of Graphic Detail (Grade) which should be strictly related to the aims of the model and to the level of accuracy of the metric survey (Fai et al., 2014; Lo Turco et al., 2016). From a purely graphic point of view, the resolution degrees of the identified models can be divided into (Figure 11):

- Grade 1: coarse, a three-dimensional processing with minimum possible detail, consistent to 1:200 scale ;

- Grade 2: medium, a three-dimensional model with a good detail level, such to identify its topological, formal, and dimensional characteristics, and partly also its metric characteristics, consistent to $1: 100$ scale ;

- Grade 3: fine, a three-dimensional model equal to the one in Grade 2 in terms of technical and informative aspects, but with much more accurate graphic features, with a photorealistic representation, consistent to 1:50 scale.

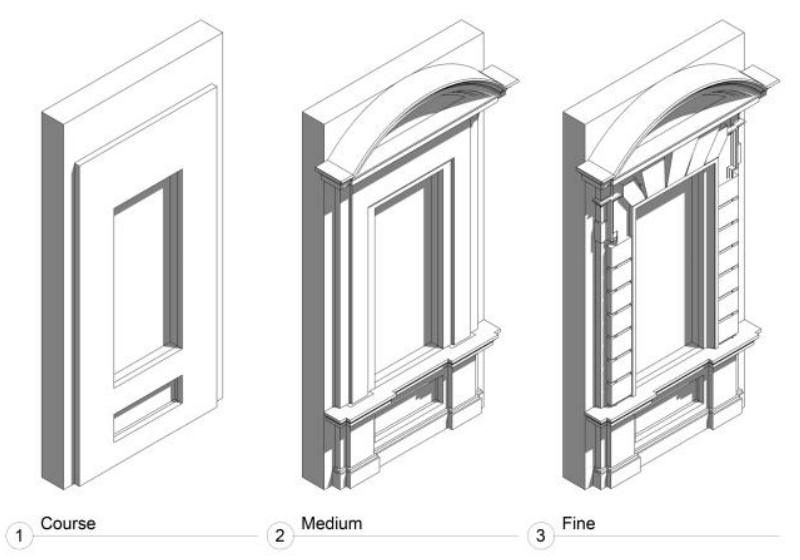

Figure 11.3D modeling of the same building component according to several Graphic Details (GraDe).

\subsection{Data enrichment}

As known, the BIM database is able to recover such information, very useful for professionals involved in the restoration, intervention or management of existing buildings.
Doing that, we need to include other variables, critically analyzing the richness of information available (Figure 12); the implemented database is very useful because it could give indication on survey reliability degree.

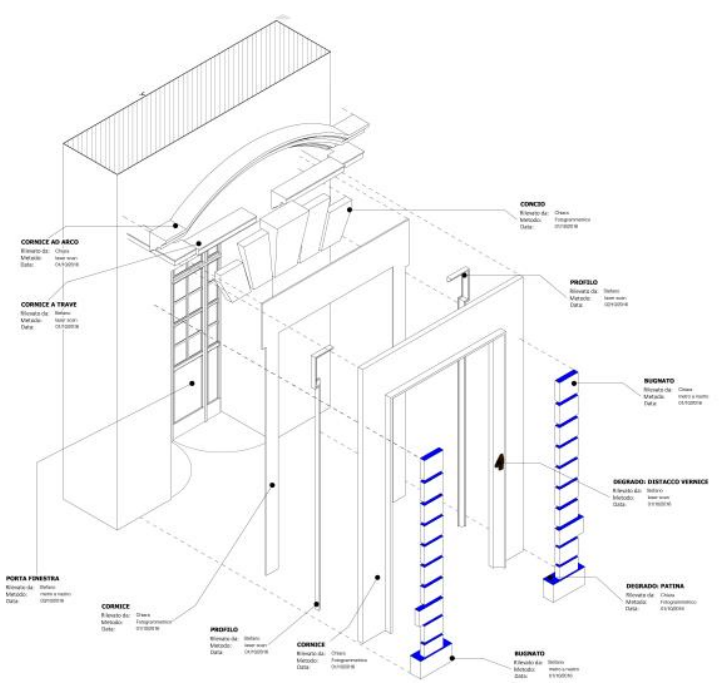

Figure 12. Exploded axonometry that shows the complex semantic decomposition of each single architectural subcomponent

More the survey process is complete, greater the integration with the various stakeholders who participated in the study can be arranged. At the regard, the last researches conducted in the Restoration field allow to make the relationship between different skills even closer, bidirectionally relating graphic sign and information.

Going more into depth, the final step consisted on the modeling of 3D decays in the BIM platform, enriching the related database with graphic, geometric and alphanumeric data that can be effectively used to design and manage future interventions (Figure 13). In literature, the most wellestablished procedures provide the graphic representation of different decays through the overlapping of 2D patterns. Usually this kind of representation are done directly on drawings, which are orthogonal projections. When the object of study is characterized by curved surface (walls, vaulted surfaces, etc..), this information is not properly given.

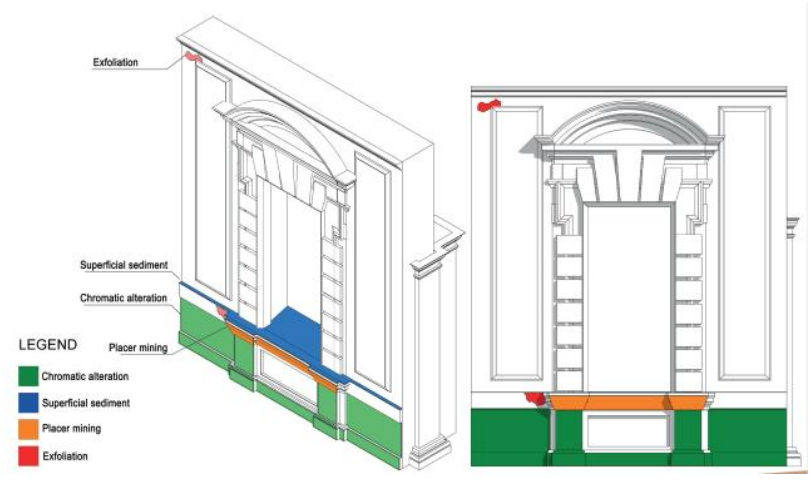

Figure 13. 3D modeling of the decays using specific adaptive component able to adhere both to planar and to curved surfaces and very useful to collect many kinds of data 
Moreover, working on a 3D textured model (i.e. a textured mesh) this issue can be overcome because the mapping is directly done on 3D surfaces and the computed quantities are correct (Lo Turco et al., 2016).

Another issue deals with the difficulty to associate parameters to detail 2D representations. In the parametric modeling environment it is possible to use adaptive $3 \mathrm{D}$ components able to adhere to each surface and, at the same time, to record not geometrical information such as: decay classification, date, author of the surveying, assembled system and degraded finishing material, ID code and description of the proposed interventions

\subsection{D models sharing and interoperability}

Finally, we have tested some website platforms able to recover such models to enlarge the digital patrimony of components that can be reconducted to Cultural Heritage and to share both the results and our mature awareness and knowledge.

The final step was aimed at the sharing of the models on web platforms, such as SketchtFab, designed for 3D model sharing. It provides a 3D model viewer based on the WebGL technology that allows to display 3D models on any mobile, desktop webpage or VR headset. The sharing on the web, on a platform used by several users represents a fundamental passage in the valorization of cultural heritage and democratization of science, giving visibility to the workshop results. Unlikely, the web site allows the upload of textured mesh models using OBJ format. Thus, it was not possible to upload neither the point clouds or the enriched Revit model. However the libraries and all the materials created within the workshop are available on Dropbox or GDrive

\section{CONCLUSIONS}

Nowadays the last improvement of the survey techniques based on the generation of 3D point clouds allow to realize fast and accurate survey for the architectural knowledge. Up to the last years the better way for obtaining a complete point cloud was the use of TLS that is able to generate very dense point cloud with a controlled accuracy.

Therefore, Computer Vision algorithms allow to extract 3D point clouds using the well known photogrammetric workflow in a more automatic way. The easily use of those new generation of software enormously improve the programs that allow to extract 3D information. In this scenario, it is important to understand how the software works and not use it as black box for controlling the results and the achieved accuracy of the final output.

This was one of the first goal of the workshop carried out in the area of the Valentino Castle. Starting from this fundamental assumption the work has carried out using two software, controlling the results in terms of generated information (density of the point cloud) an accuracy using the TLS data as ground truth. The obtained results were acceptable according to the scale of the needed final output that was fixed at 1:50.

The generation of the parametric 3D model was obtained starting from the point clouds using the plug-in Pointsense for Revit which allowed us to handle the obtained point clouds in Revit family editor. The modeling phase highlighted the importance of a historical knowledge-base approach for the semantic identification of architectural components and the geometric genesis of shapes as well as the need to set up the level of detail of the model, according to architectural surveying requirements.

Then we focused on data enrichment issues, considering both infographic documentation and the modelling of decays directly on 3D surfaces dealing with the difficulty to associate parameters to detailed 2D representations.

Doing that, now, the information is not fragmented: it is assumed to have produced a research that aims at improving the efficiency and effectiveness of more conventional procedures. The final models synthesize the information usually fragmented enriching it with new methods of analysis and management of data, opening the way to new scenarios of "knowledge".

\section{ACKNOWLEDGEMENTS}

Authors would like to thank the colleagues of the teaching team: Prof. A. Dameri, Dr. M. Marcucci, Prof. M. Mattone, Prof. M. Naretto, Arch. G. Sammartano.

The authors would like to thank Kubit software and Faro Europe (Alberto Sardo) for their kind authorization to use Pointsense for Revit plug-in for research purposes.

\section{REFERENCES}

Apollonio, F.I., Gaiani, M., Sun, Z., 2013. 3D modeling and data enrichment in digital reconstruction of architectural heritage. The International Archives of the Photogrammetry, Remote Sensing and Spatial Information Sciences XL-5/W2, pp. 43-48.

Biagini, C., Capone, P., Donato, V., Facchini, N., 2016. Towards the BIM implementation for historical building restoration sites. Automation in Construction, 71, pp. 74-86.

Bonacini, E., Marcucci, M., Todisco, F., 2014. \#DIGITALINVASIONS. A bottom-up crowd example of cultural value co-creation. Information Technologies for Epigraphy and Digital Cultural Heritage, Proceedings of the First EAGLE International Conference 2014, September 29-30 and October 1, 2014, Paris. pp. 265-284.

Brumana, R., Oreni, D., Raimondi, A., Georgopoulos, A., and Bregianni, A., 2013. From survey to HBIM for documentation, dissemination and management of built heritage: The case study of St. Maria in Scaria d'Intelvi. Digital Heritage 2013 pp. 497 504.

Chiabrando, F., Spanò, A. 2013. Points Clouds Generation Using Tls and Dense-Matching Techniques. a Test on Approachable Accuracies of Different Tools. The International Archives of the Photogrammetry, Remote Sensing and Spatial Information Sciences Volume II-5/W1, pp. 67-72

Chiabrando, F., Sammartano, G., Spanò, A. 2016. Historical buildings models and their handling via $3 \mathrm{~d}$ survey: From points clouds to user-oriented hbim. The International Archives of the Photogrammetry, Remote Sensing and Spatial Information Sciences, pp. 633-640.

De Luca, L., Vèron, P., Florenzano, M., 2005. Semantic-based modelling and representation of patrimony buildings. SVE Worksop towards Semantic Virtual Environments, Mar 2005, Villars, Switzerland. pp.1-11, 2005.

De Luca, L., 20016. Relevé et multi-représentations du patrimoine architectural Définition d'une approche hybride de reconstruction d'édifices. Thèse de l'ecole doctorale Arts et Metiers ParisTech, Aix-en-Provence, mars. 
Del Giudice, M., Osello, A., 2013. BIM for cultural heritage. The International Archives of the Photogrammetry, Remote Sensing and Spatial Information Sciences, Volume XL-5/W2, pp 225-229.

Fai, S., Graham, K., Duckworth, T., Wood, N., Attar, R., 2011. Building information modelling and heritage documentation. 23rd CIPA Symposium, Prague, Czech Republic. 8 pages.

Fai, S., Rafeiro, J. 2014. Establishing an Appropriate Level of Detail (LoD) for a Building Information Model (BIM) - West Block, Parliament Hill, Ottawa, Canada. ISPRS Annals for the Photogrammetry, Remote Sensing and Spatial Information Sciences II-5 pp. 123-130.

Gaiani, M., Remondino, F., Apollonio, F.I., Ballabeni, A., 2016. An Advanced Pre-Processing Pipeline to Improve Automated Photogrammetric Reconstructions of Architectural Scenes. Journal of Remote Sensing. 8(3), 178.

Grussenmeyer, P., Landes, T., Boegtle, T., Ringle, K., 2008. Comparison methods of terrestrial laser scanning, photogrammetry and tacheometry data for recording of cultural heritage buildings. The International Archives of the Photogrammetry, Remote Sensing and Spatial Information Sciences. XXXVII/ B5. pp 213-218

Hichri, N., Stefani, C., De Luca, L., Véron, P., Hamon, G., 2013. From Point Cloud To BIM: a Survey of Existing Approaches. The International Archives of the Photogrammetry, Remote Sensing and Spatial Information Sciences, XL-5/W2, pp.343-348

Kadobayashi, R., Kochi, N., and Furukawa, R. 2004. Comparison and Evaluation of Laser Scanning and Photogrammetry and Their Combined Use for Digital Recording of Cultural Heritage. The International Archives of the Photogrammetry, Remote Sensing and Spatial Information Sciences, 35 (Part B5). pp 401-406

Inzerillo, L., and Santagati, C., 2013. Using dense stereo matching techniques in survey. Disegnare Idee Immagini, 47, pp. 82-91

Lichti DD, Gordon SJ, Stewart MP, Franke, J., Tsakiri, M., 2002. Comparison of digital photogrammetry and laser scanning. Proceedings of International Workshop on Scanning for Cultural Heritage Recording - Complementing or Replacing Photogrammetry, Corfu, Greece, September 1-2. pp 39-44.

Lo Turco, M., Caputo, F., and Fusaro, G., 2016. From Integrated Survey to the Parametric Modeling of Degradations. A Feasible Workflow. In: Euromed 2016, LNCS 10058. Springer, Heidelberg, pp. 579-589.

Lo Turco, M. and Santagati, C. 2016. From SfM to SemanticAware BIM Objects of Architectural Elements. In: EuroMed 2016, Part I, LNCS 10058. Springer, Heidelberg, pp 600-612

Manferdini, A., M., and Galassi, M., 2013. Assessments for 3d reconstructions of cultural heritage using digital technologies. The International Archives of the Photogrammetry, Remote Sensing and Spatial Information Sciences, XL-5 W, pp. 167174.

Murphy, M. McGovern, E., Pavia, S. 2013. Historic Building Information Modelling - Adding intelligence to laser and image based surveys of European classical architecture. ISPRS Journal of Photogrammetry and Remote Sensing, 76, pp. 89-102.

Oreni, D., Brumana, R., Georgopoulos, A. Cuca, B., 2013. Hbim for Conservation and Management of Built Heritage: Towards a Library of Vaults and Wooden Bean Floors. ISPRS Annals of the Photogrammetry, Remote Sensing and Spatial Information ScienceII-5/W1, pp- 215-221.

Quattrini, R., Malinverni, E. S., Clini P, Nespeca, R., and Orlietti, E., 2015. From TLS to HBIM. High quality semantically-aware 3D modeling of complex architecture. The International Archives of the Photogrammetry, Remote Sensing and Spatial Information Sciences XL-5/W4, pp. 367-374.

Quattrini R., Clini P., Nespeca R., Ruggeri L., 2016. Measurement and Historical Information Building: challenges and opportunities in the representation of semantically structured 3D content. Disegnarecon, 9 (11), pp. 1-11.

Remondino, F., Spera, M.G., Nocerino, E., Menna, F., Nex F., 2014. State of the art in high density image matching. The Photogrammetric Record, 29, pp. 144-166.

Remondino, F., 2011. Heritage recording and 3D modeling with photogrammetry and 3D scanning. Remote Sensing, 3(6), pp. 1104-1138.

Roncella, R., Re, C., Forlani, G., 2011. Performance evaluation of a structure and motion strategy in architecture and cultural heritage. The International Archives of the Photogrammetry, Remote Sensing and Spatial Information Sciences 38 (5/W16), pp. 285-292.

Santagati, C., Lo Turco, M., 2017. From structure from motion to historical building information modeling: populating a semantic-aware library of architectural elements, Journal of Electronic Imaging. 26(1), 011007: 1-12.

Spanò, A., Guardini, N., 2012. A sustainable approach in 3d documentation for historical building restoration. Valentino castle building yard, In: proceedings 5th International Conference Science and technology for the Safeguard of Cultural Heritage in the Mediterranean Basin, Vol. 1, pp. 134143.

Tang, P., Huber, D., Akinci, B., Lipmand, R., Lytlee, A., 2010. Automatic reconstruction of as-built building information models from laser-scanned point clouds: A review of related techniques. Automation in Construction, 19, pp. 829-843.

Thomson, C., and Boehm, J., 2015. Automatic geometry generation from point clouds for BIM. Remote Sensing, 7, pp. 11753-11775.

To, T., Nguyen, D., Tran, G., 2015. Automated 3D architecture reconstruction from photogrammetric structure-and-motion: A case study of the One Pilla pagoda, Hanoi, Vienam. The International Archives of Photogrammetry, Remote Sensing and Spatial Information Sciences, 40(7), 1425.

Volk, R., Stengel, J., and Schultmann, F., 2014. Building Information Modeling (BIM) for existing buildings - Literature review and future needs. Automation in Construction, 38, pp. 109-127. 